approach may differ from that of their colleagues, often to a surprising degree, particularly in dose and fractionation. In the south of England, for instance, a radical course of therapy may take six weeks, whereas colleagues at the Christie Hospital in Manchester, the largest radiotherapy centre in Europe, would hardly ever treat a patient for longer than three weeks. For a given clinical problem, therefore, the overall dose of radiotherapy might well vary by a factor of at least $25 \%$. Furthermore, refinements in technique may lead within a relatively short time to revisions in dosage; for treast conserving carcinoma of the breast, for example, the radiation dose given by one of the Exeter consultants still remains lower than the dose he would have given under similar circumstances five years ago, even including the unintentional $25 \%$ excess.

None the less, a serious error has been made, though only a small minority of patients are at serious risk of damage. Patients who were treated palliatively, many of whom had widespread metastases, are unlikely to survive long enough to suffer severe damage; in any event palliative doses are often low so a $25 \%$ additional dose would be relatively harmless.

Professor Charles Joslin from the University of Leeds has already started an independent inquiry into this accident, and his findings will be made available to the regional health authority. It already seems clear that a small number of patients are indeed at high risk of radiation damage, which could be extremely serious-for example, laryngeal necrosis, rectal stenosis, and fistula. In a recent high court case a claim for damages was made against a health authority after a laryngectomy was performed for laryngeal radionecrosis, necessitated by a course of treatment in which a similar error of dose calculation led to an unexpectedly high dose.

One clear lesson from this unfortunate business is that calibration of a new cobalt source must be checked and rechecked, with better communication between the hospital physicist and the suppliers, who should have an accurate record of the likely output of the source to be installed. It is certainly possible to cross check a new installation in this way, and it might even be sensible to repeat the calibration of a new source a month after its first use in case of contamination with other isotopes which might have unexpected patterns of decay. There will also be far reaching consequences for the Hospital Physicists' Association, which is properly arguing for increased status for medical physicists and may now have to turn its attention to the question of insurance and indemnity for its members.

Consultant in Radiotherapy and Oncology,

JEFFREY S TOBIAS

University College Hospital,

London WC1E 6AU

1 National Radiological Protection Board. (iuddance notes for the protectum of persoms aguinst iomsing radiutions arising from medical and dental use. London: HMSO, 1988.

\title{
Social network interaction: new jargon in health inequalities
}

\author{
Whom you know may be important for your health
}

Gomer and Johnson have recently described the relations between social network interaction and mortality.' This horrible piece of jargon has grown out of the increasing evidence on psychosocial factors and their effects on health. The phrase should not be forgotten because it seems important in explaining patterns of mortality.

Interest in differences in mortality among social groups has re-emerged in the past 10 years both internationally ${ }^{2}$ and nationally. ${ }^{3}$ This follows a long period when it was assumed in most developed countries that reorganisation of health and social welfare provision after the second world war had reduced or even eliminated the major differences among the social groups and the discovery in the late 1960s that this was not the case. ${ }^{+}$Differences in mortality among social groups were expected to decline because the poorest were protected by administrative changes. It was assumed that socioeconomic inequalities had declined and that the general rise in living standards among young people had virtually eliminated the so called "diseases of poverty."

Interest in inequalities re-emerged at a time when it seemed that the major improvements in health in the early part of the century were slowing down and even stopping. Infectious diseases, particularly tuberculosis and respiratory disease, were examples of causes of death with strong links to poverty, whose importance had obviously diminished. It came as a surprise, then, when in the 1960 s and 1970s many causes of death that had not previously shown any tendency to be related to social class started to develop the now widely accepted pattern of low mortality among professionals and high mortality among semiskilled and unskilled manual workers. ${ }^{5}$

The pattern of social inequality in health that has emerged in recent years has led to greater emphasis being placed on explanations and on the search for factors that may exert a more general influence on health but which are further back in the causal chain. ${ }^{6}$ Since 1980 there has been limited evidence that these inequalities are an artefact of the method used to produce the official statistics and that differences are caused by health related mobility among social classes (the social selection hypothesis). These explanations have, however, been measured and shown to be unimportant.

As Syme suggested, social epidemiologists should investigate "ways in which a person's position in the social structure influences the likelihood that he will develop disease." This includes differences in resistance and response to the social environment as well as differences in environmental stressors." Cassel asked, "Are there categories or classes of environmental factors that are capable of changing human resistance in important ways and making subsets of people more or less susceptible to these ubiquitous agents in our environment?" $\mathrm{He}$ went on to argue that "the presence of other members of the same species, or, more generally, certain aspects of the social environment would be one such category of environmental factor."10

\section{Resources for coping}

Valkonen claims that interest in general factors has been stimulated not just by the pattern of mortality differences among social classes now being observed for most causes of death. Another reason is that studies such as the Whitehall study fail to explain with known risk factors a large fraction of differences that are observed in particular causes of death such as coronary heart disease. ${ }^{21}$ In the search for general 
explanations Antonovsky focuses attention on people's resources for coping with different exposures. He suggests that those in lower socioeconomic groups have less money, knowledge, intelligence, and social contacts to help them cope successfully in adversity. ${ }^{12}$

Social networks are becoming of central importance to the growing published reports on psychosocial factors in health. ${ }^{13}$ Cassel's work led several researchers to investigate relations among social networks, social support, isolation, and social integration and mortality. The first study, in Alameda County, "was meant to be thought provoking and to stimulate research in the area of how human relationships might influence physical health." ${ }_{14}$ In support of Cassel's arguments evidence has accumulated from prospective community cohort studies $^{15-18}$ and studies in Sweden ${ }^{19}$ and Hawaii. ${ }^{20}$ Further support has come recently from a national population sample and from further analysis of the Alameda County Study. ${ }^{21}$

\section{Important differences}

Berkman highlighted differences in findings among studies in magnitude of effect, between men and women, and between age groups and reiterated her call for more research on what is meant by social networks and social support as well as on how they affect health. ${ }^{1422}$ The Alameda County study explored four categories of social network: marital state, friends and relatives, church membership, and group membership. Each was related to mortality after controlling for other relevant factors, and, as the recent extension of the study shows, the importance of each varies with age. "Unfortunately, virtually none of the studies linking either social networks of social support to mortality or morbidity employ sophisticated measures of these variables. If the strength of these studies lies in the rigorous assessment of outcomes, their weakness almost uniformly lies in the assessment of independent variables." 22

No information was collected on several characteristics of social networks and social support, and so there is doubt about whether the critical dimension has been measured. Different dimensions have been picked up in subsequent studies, but often researchers are restricted in the range of questions asked of people interviewed. For example, the recent Swedish study uses questions asked about social networks in the national survey of living conditions, linking the population interviewed to national mortality files.' Responses to 18 questions about social networks were obtained. These included contact with parents, children, other relatives, and friends from childhood and contacts within the neighbourhood and with colleagues from work. Again they covered only two aspects of social networks - the number and type of sources of contact and the degree of contact with each. As with previous studies responses to individual items were summarised in a single index - in this case called the "social network interaction index."

\section{Mediating mechanisms}

Though the jargon is unnecessary, such technical indices will be needed to summarise the increasingly complex data collected by these studies. Berkman has suggested an exten- sive range of characteristics of networks that will need to be investigated if we are to understand how they mediate the effects of environmental stressors. ${ }^{22}$ These include the number of people in a person's network, how often people are seen, the extent of interaction between different members of a network, the feeling of closeness to members of the network, the length of time the person had been concerned with the network, the geographical proximity of network members, and the extent to which network members help each other.

The indices being developed are, however, only cross sectional describers. To understand the processes at workfor example, the changes that occur when particular ties such as marriage are broken-further studies based on longitudinal measures will be needed. These could illustrate the diverse paths to specific outcomes and the range of consequences of particular changes. Although the questions to be addressed increase in complexity, their importance to a general understanding of differences in health among different sections of the community seems well established.

Director and Professor of Social Statistics,

JOHN FOX

Social Statistics Research Unit,

City University,

London EClV $0 \mathrm{HB}$

1 Orth-Gomer K, Johnson JV. Social network interaction and mortality: a six year follow-up study of a random sample of the Swedish population. F Chronic Dis 1987;40:949-57.

Valkonen T. Social inequality in the face of death. In: European Population Association conference 1987. Helsinki: Central Statistics Office, 1987:201-60.

3 Whitehead M. The health divide: inequalities in health in the 1980s. London: Health Education Council, 1987.

4 Antonovsky A. Social class, life expectancy and overall mortality. Millbank Mem Fund $Q$ 1967;45:151-93

5 Office of Population Censuses and Surveys. Occupational mortality 1970-72. London: HMSO, 1978 (Decennial Supplement Series DS No 1.)

6 Marmot MG. Epidemiology and the art of the soluble. Lancet 1986;: $897-900$

7 Wilkinson RG. Class and health: research and longitudinal data. London: Tavistock, 1986.

8 Syme SL. Behavioural factors associated with the etiology of physical disease: a social epidemiological approach. Am 7 Public Health 1974;64:1043-5.

9 Antonovsky A. Breakdown: a needed fourth step in the conceptual armamentarium of modern medicine. Soc Sci Med 1972;6:537-44.

10 Cassel J. The contribution of the social environment to host resistance. Am f Epidemiol 1976;104:107-23.

11 Marmot MG, Shipley MJ, Rose AG. Inequalities in death: specific explanations of a general pattern. Lancet 1984;ii: 1003-6.

2 Antonovsky A. Health, stress and coping. London: Jossev-Bass, 1979

13 Coronary Prevention Group. Does stress cause heart attacks? London: CPG, 1986

14 Berkman LF. Social networks, support and health: taking the next step forward. Am 7 Epidemiol 1986;123:559-62.

15 Berkman LF, Syme SL. Social networks, host resistance and mortality: a nine year follow-up study of Alameda County residents. Am F Epidemiol 1979;109:186-204

16 House JS, Robins C, Metzner HL. The association of social relationships and activities with mortality: prospective evidence from the Tecumseh Community Health Study. Am 7 Epidemiol 1982;116:123-40

17 Blazer DG. Social support and mortality in an elderly community population. Am $\mathcal{J}$ Epidemiol 1982;115:686-94

18 Schoenbach VJ, Kaplan BH, Fredman L, et al. Social ties and mortality in Evans County, Georgia. Am f Epidemiol 1986;123:577-91.

9 Welin L, Tibblin G, Svardsudd K, et al. Prospective study of social influences on mortality. Lance $1985 ; \mathrm{i}: 915-8$.

20 Reed D, McGee D, Yano K, et al. Social networks and coronary heart disease among Japanese men in Hawaii. Am f Epidemiol 1983;117:384-96.

21 Seeman TE, Kaplan GA, Knudsen L, Cohen R, Guralnik J. Social network ties and mortality among the elderly in the Alameda County Study. Am $\mathcal{F}$ Epidemiol 1987;126:714-23.

22 Berkman LF. Assessing the physical health effects of social networks and social support. Annu Rev Public Health 1984;5:413-32.

23 Berkman LF. Assessing social networks and social support in epidemiologic studies. Rev Epidemiol Sante Publique 1987;35:46-53.

\section{Correction}

Alcohol services: exhortations rather than commitment

In the first sentence of the last paragraph of Dr P Caviston's editorial on alcohol services (23 July, p 241) the interministerial committee on alcohol problems was wrongly called the international committee on alcohol problems. This error arose at the typesetters and was not picked up by our proof readers. 